\title{
Effects of Medicinal Plants Extract with Antibiotic Free Diets on Broilers Growth Performance and Incidence of Muscles Abnormalities
}

EAuthor(s)

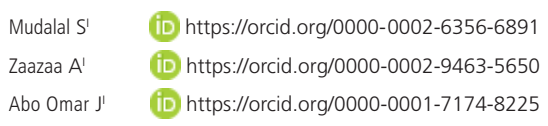

Faculty of Agriculture and Veterinary Medicine, An Najah National University, Nablus, P. O. Box 707, Palestine.

\section{nail Address}

Corresponding author e-mail address Jamal Abo Omar

Faculty of Agriculture and Veterinary Medicine, An Najah National University,

Nablus, P. O. Box 707, Palestine.

Phone: + 970599205476

Email: aboomar57@najah.edu

\section{ABSTRACT}

The objective of this research was to investigate the effects of a natural herb extract ${ }^{1}(\mathrm{HE})$ on the general growth performance and the incidence of muscle abnormalities (white striping and wooden) of broiler chicks. A total of 504 one-day old chicks (Ross 500) were used in the experiment and randomly partitioned into 3 treatments with 7 replicates in each (24 chicks per replicate). Three experimental diets (C: regular feed; T1 and T2 (supplemented with HE at levels of 0.20 and $0.30 \mathrm{ml} / \mathrm{L}$, respectively). The herbal extract was supplemented in drinking water. Feed intake, body weight and feed conversion ratio were monitored at days 14, 28 and 42 of the feeding trial. Moreover, the yield of visceral organs, carcass cuts, and the incidence of muscle abnormalities were evaluated at different ages of slaughter (34, 41and 48 days). Results showed that weights, feed conversion ratios (FCR) and dressing percentages (DP) increased $(p<0.05)$ in birds supplemented with herb extract compared to control birds. However, HE supplementation had no significant effects on carcass cuts and some visceral organs. Meat quality was improved by HE supplementation as the incidence of white stripping (WS) and WS plus wooden meat cases dramatically reduced, in particular at 34 days of age, day of slaughter. It can be concluded that feeding the herbal extract has significant positive effects on broilers general performance, feed efficiency and meat quality.

\section{INTRODUCTION}

The use of antibiotics is restricted in many parts of the world. However, $80 \%$ of raised livestock were fed some kind of antibiotics or growth promoters. Recently, herbs extract were fed as nontraditional feed additive to replace the growth promoters and antibiotics Lee et al., 2001). Herbal extracts were used in the extensive livestock system to improve animals' general performance (Abo Omar et al. 2016; Bakhiet \& Adam, 1995; Gill et al. 2002; Horton et al., 1991; Janssen, 1989; Manzanilla et al., 2001; Skrabka et al., 1997; William \& Losa, 2001). The positive effects of herb extracts were due to the improvement of feed intake, digestibility, activation of the immune system and the anthelmintic actions. Fenugreek was reported to have positive effects on the digestive system (Raju et al., 2004) and to be rich in protein, total carbohydrates and minerals, Gupta et al. (1996)[10].

Kolacz et al. (1997) reported that the excessive growth of gastrointestinal tract, harmful microorganisms and inflammations were minimized by feeding chamomile flowers. It was found that Nettle (Urtica dioica) which is composed of starch, gum, albumen,

Herb extract $(\mathrm{HE})$ is a mixture of pure honey with an extract of several medicinal plants: fenugreek (Tigonella foenum graecum), chamomile (Anthemis ecutita), nettle (Urtica dioica), thyme (Thymusvulgaris), mint (Menthola), black seed (Nigella sativa). 
sugar, histamine, acetylcholine, choline, and serotonin is fed to animals. Thyme (Thymus vulgaris) is also used for medicinal purposes through its components (thymol, 40\% and carvacrol, 15\%) (Mikaili et al., 2010). Mentha species of the family labiatae have antiseptic properties and improve digestibility which have beneficial effects on digestion (Foster \& Duke, 1999). Studies on the pharmacological action of active plant substances or herbal extracts in animal nutrition is relatively limited.

Currently, there is a great demand on broiler meat and there is a great success in increased growth rate in order to optimize the production of this meat. The improvement of growth rate resulted in high incidence of muscle abnormalities. The most recent and emerging muscle abnormalities are white striping (WS) and wooden abnormalities (WA) (Petracci et al., 2019). In addition, visible/near infrared spectroscopy has been investigated to differentiate between normal and white striped meat (Zaid et al., 2019)

Mudalal (2019) reported that the total incidence of white striped breast fillets under commercial conditions in different genotypes of broilers was very high and reached up to $61.3 \%$. Considering the effect of genotype, the results showed that high-breast yield hybrids exhibited a higher overall incidence of WS compared with standard-breast yield hybrids (Petracci et al., 2019).

The objective of this research was to investigate effects of a blend of natural herb extract on growth performance and incidence of muscles abnormalities of broilers reared under antibiotics free rations.

\section{MATERIALS AND METHODS}

\section{Experimental animals and design}

A total of 504 one-day old chicks (Ross 500) were purchased from a local hatchery. At the experimental site, chick's initial weights were recorded and randomly housed in wood shavings covered floor pens. Chicks were divided into 3 treatments with 168 birds in each pen and to 7 replicates per treatment in a complete random design. Continuous lighting was provided throughout the experiment. The ambient temperature was gradually decreased from $32^{\circ} \mathrm{C}$ on day 1 to $7^{\circ} \mathrm{C}$ to $24{ }^{\circ} \mathrm{C}$ on day 21 and was then kept constant.

The diet's ingredients components fed and their chemical analysis are presented in Table 1. The starter diets were fed for the first three weeks and the grower diet was fed for the remainder of the trial (48 days).
Chicks were assigned to the control diet (control, C) which is similar to regular broiler starter diets. While the experimental treatments T1 and T2 birds were fed the diets as in control but was supplemented with the herb extract at levels of 0.2 and $0.3 \mathrm{ml} / \mathrm{L}$ in drinking water. Birds diets were formulated to meet the NRC (1990) recommendations. Feed intake was recorded in a weekly basis, by deducting the amount of feed that remained in the feeders at end of the week from the amount offered. Individual bird weight was also recorded in a weekly basis. Birds' mortalities within the five days were replaced, afterwards, mortality was recorded as it occurred and dead chick weights were determined where possible.

Table 1 - Composition of the basal diets fed to broilers in feeding trial, $\mathrm{g} / \mathrm{kg}$.

\begin{tabular}{lcc}
\hline Ingredient & Starter & Grower \\
\hline Yellow corn & 560 & 620 \\
Soybean meal & 360 & 306 \\
Oil & 40 & 40 \\
DCP1 & 15 & 12 \\
Limestone & 15 & 15 \\
$\mathrm{NaCl}$ & 3.5 & 3.5 \\
Premix & 5 & 5 \\
DL-methionine & 1 & 1 \\
L- lysine & 0.5 & 0.5 \\
Calculate analysis & & \\
Crude protein & 220 & 200 \\
Lysine & 110 & 110 \\
Methionine & 55 & 56 \\
Calcium & 100 & 110 \\
Available P & 46 & 47 \\
ME, MJ/ kg ration & 704 & 718 \\
\hline
\end{tabular}

'Dicalcium phosphate. ${ }^{2}$ Vitamin premix/kg diet: vitamin A, 12,000 IU; vitamin D3, 1500 IU; vitamin E, 50 mg; vitamin K3, 5 mg; vitamin B1, 3 mg; vitamin B2, 6 mg; vitamin B6, 5 mg; vitamin B12, 0.03 mg; niacin, 25 mg; Ca-D-pantothenate, 12 mg; folic acid, $1 \mathrm{mg}$; D-biotin, 0.05 mg; apo-carotenoic acid ester, $2.5 \mathrm{mg}$; choline chloride, $400 \mathrm{mg}$.

Body weight (BW), feed intake (FI) and feed conversion ratios (FCR) were assessed on days 14,28 and 42 or during the age ranges of 1-14, $14-28$ and 28 - 42 days. FCR was calculated as the following: $F C R=$ average feed consumed/average live weight

\section{Visceral organs and carcass cuts}

At $42 \mathrm{~d}$ of age, eight birds per replicate were slaughtered through cutting carotid arteries and partial slicing of the neck by a manual neck cutter. Carcass yield was calculated by dividing eviscerated weight by live weight. Visceral organs (liver, gizzard, heart, proventriculus, small intestine, cecum) and abdominal fat were weighed and calculated as a percentage of live body weight and also carefully examined to detect any pathological lesion or damage. Carcass parts were measured as percent of carcass weight. 


\section{Assessment the incidence of muscle abnormalities}

After about $8 \mathrm{hr}$ of post mortem, breast fillets from all treatments and replicates were collected to assess the incidence of muscle abnormalities. Based on previously described criteria by Kuttappan et al. (2012b) and Sihvo et al. (2014), the muscle abnormalities were classified into four categories (Normal, white striping, wooden, and white striping/wooden). Breast fillets were labeled as normal $(\mathrm{N})$ when there were no white striations or hardened areas over the surface. When breast fillet exhibited white striations (thin to thick striations) on the surface, it was labeled as white striped fillet (WS). In the case of presence of pale ridge-like bulges and diffuse hardened areas, breast fillet was labeled as wooden breast (WB). Finally, when a fillet was affected by both muscle abnormalities white striping and wooden breast, it was labeled as WSMB.

\section{Statistical analysis}

The results of the study were analyzed using the ANOVA (GLM procedure SAS statistical analysis software, 2002). It was used to evaluate the effect of herbs extract (two levels of inclusion) and replicates on the growth performance, feed conversion ratio, and the incidence of muscle abnormalities. Duncans test was employed to separate the mean value in the case of presence of statistical differences $(p>0.05)$. Pearson correlation was used to test the relationship between pairs of continuous variables (i.e., feed con-version ratios, carcass and visceral organ variables).

\section{RESULTS}

\section{Feed intake}

Results showed that the feed intake was significantly increased in group $\mathrm{T} 1$ and $\mathrm{T} 2$ if compared to control group $C$ at age 1-14d (35.52 and 36.09 vs. $34.74 \mathrm{~g} / \mathrm{d}, p<0.05)$ and age 1-42d (118.29 and 118.03 vs. $117.10, p<0.05)$. The HE significantly increased $(p<0.05)$ feed intake when fed at 0.2 and $0.3 \mathrm{ml} / \mathrm{L}$ compared to the control birds during the entire feeding trial (Table 2).

\section{Body weight}

Birds supplemented with the two levels of the extract gained more $(p<0.05)$ weight at all growth periods compared to birds consuming the regular broiler diet (Table 2).

Body weight significantly increased in birds of group T1 and T2 compared to the control at ages 1-14 $d(456.4,481.0$ vs. $434.4 \mathrm{~g}, p<0.05), 1-28 \mathrm{~d}$ (1462.06, 1513.27 vs. $1412.09 \mathrm{~g},(p<0.05)$ and $1-42 \mathrm{~d}(2574.3$, 2671.4 vs. $2486.2 \mathrm{~g},(p<0.05)$ Table 2.

\section{Feed conversion ratio}

HE had positive effects on FC ratio. FCR significantly improved in birds of groups T1 and T2 compared to the control group birds at age of $28 \mathrm{~d}(1.530,1.476 \mathrm{vs}$. $1.578, p<0.05)$. However, HE had variable effects on FCR where T2 birds had better feed efficiency compared to T1 birds (1.476 vs. 1.530, p<0.05). At $42 \mathrm{~d}$ of the feeding trial, FCR in birds of T1 and T2 was similar but significantly lower compared to that of control birds $(2.100,2.183$ vs. 2.249, $p<0.05)$. For the entire feeding period, the FCR that most improved was in birds of T2 followed by T1 and control (1.667 vs. $1.734,1.785, p<0.05)$, Table 2 .

\section{Visceral organs}

Visceral organs were expressed as percentages of live weights. HE had no effects on abdomen fat, pancreas, and hear. However, there was a numerical difference

Table 2 - Effect of herb extract (HE) supplementation on performance indices of broilers at different ages. The basal diet (control, C) which is similar to regular broiler starter diets. While the experimental treatments T1 and T2 birds were fed the diets as in control but was supplemented with the herb extract at levels of 0.2 and $0.3 \mathrm{ml} / \mathrm{L}$ in drinking water.

\begin{tabular}{|c|c|c|c|c|c|}
\hline & & $C$ & T1 & $\mathrm{T} 2$ & $p$ value \\
\hline \multirow[t]{4}{*}{ Feed intake } & $1-14 d$ & $34.75^{b}$ & $35.52^{a}$ & $36.09^{a}$ & 0.002 \\
\hline & $14-28 d$ & 110.19 & 109.93 & 108.76 & 0.07 \\
\hline & $28-42 d$ & 172.29 & 173.47 & 173.27 & 0.358 \\
\hline & $1-42 d$ & $117.10^{b}$ & $118.29^{\mathrm{a}}$ & $118.03^{a}$ & 0.001 \\
\hline \multirow[t]{3}{*}{ Body weight } & $14 d$ & $434.48^{c}$ & $456.35^{b}$ & $481.86^{a}$ & 0.000 \\
\hline & $28 d$ & 1412.09 & $1462.06^{b}$ & $1513.27^{a}$ & 0.000 \\
\hline & $42 d$ & $2486.20^{c}$ & $2574.30^{b}$ & $2671.40^{a}$ & 0.000 \\
\hline \multirow[t]{4}{*}{ Feed conversion ratio } & $1-14 d$ & $1.11^{\mathrm{a}}$ & $1.09^{\mathrm{ab}}$ & $1.04^{a}$ & 0.005 \\
\hline & $14-28 d$ & $1.57^{a}$ & $1.53^{b}$ & $1.47^{c}$ & 0.000 \\
\hline & $28-42 d$ & $2.24^{\mathrm{a}}$ & $2.18^{b}$ & $2.10^{b}$ & 0.020 \\
\hline & $1-42 d$ & $1.78^{a}$ & $1.73^{a}$ & $1.66^{b}$ & 0.000 \\
\hline
\end{tabular}

Different letters in the same row indicate significant differences $(p<0.05)$. 
among the tested parameters. Proportions of liver to live weight was lowest in T1 birds compared to T2 and control birds (2.64 vs. 2.96, 2.92\%, p<0.05). However, the two levels of the extract ( $\mathrm{T} 1$ and $\mathrm{T} 2$ ) reduced $(p<0.05)$ the percentages of gizzard, crop and intestine percentages compared to that in control birds (Table 3).

Table 3 - Relative percentages of visceral tissues and carcass cuts of broilers supplemented with herb extract (HE). The basal diet (control, C) which is similar to regular broiler starter diets. While the experimental treatments T1 and T2 birds were fed the diets as in control but was supplemented with the herb extract at levels of 0.2 and $0.3 \mathrm{ml} / \mathrm{L}$ in drinking water.

\begin{tabular}{lcccc}
\hline Parameter & $\mathrm{C}$ & $\mathrm{T} 1$ & T2 & $p$ value \\
\hline Pancreas & 0.19 & 0.17 & 0.19 & 0.124 \\
Abdonin fat & 1.28 & 1.14 & 1.30 & 0.245 \\
Legs & 12.34 & 4.65 & 3.79 & 0.371 \\
Bursa & $0.12^{\mathrm{b}}$ & $0.11^{\mathrm{b}}$ & $0.14^{\mathrm{a}}$ & 0.000 \\
Crop & $0.72^{\mathrm{a}}$ & $0.58^{\mathrm{ab}}$ & $0.65^{\mathrm{b}}$ & 0.005 \\
Gizzard & $2.41^{\mathrm{a}}$ & $1.82^{\mathrm{b}}$ & $2.10^{\mathrm{b}}$ & 0.000 \\
Spleen & $0.19^{\mathrm{b}}$ & $0.17^{\mathrm{b}}$ & $0.20^{\mathrm{a}}$ & 0.010 \\
Liver & $2.92^{\mathrm{a}}$ & $2.64^{\mathrm{b}}$ & $2.96^{\mathrm{a}}$ & 0.000 \\
Heart & 0.57 & 0.55 & 0.55 & 0.391 \\
Intestine & $5.67^{\mathrm{a}}$ & $4.88^{\mathrm{b}}$ & $4.92^{\mathrm{b}}$ & 0.000 \\
Neck & $7.17^{\mathrm{a}}$ & $6.28^{\mathrm{b}}$ & $7.01^{\mathrm{a}}$ & 0.000 \\
Breast & 41.53 & 38.20 & 41.64 & 0.111 \\
Wings & $9.18^{\mathrm{a}}$ & $8.39^{\mathrm{b}}$ & 11.71 & 0.001 \\
Drum stick & $11.77^{\mathrm{a}}$ & 11.18 & $13.74^{\mathrm{b}}$ & 0.242 \\
Viscera & $14.87^{\mathrm{a}}$ & $12.96^{\mathrm{b}}$ & $3.13^{\mathrm{b}}$ & 0.000 \\
Live weight & $3.20^{\mathrm{a}}$ & $2.97^{\mathrm{b}}$ & $77.5^{\mathrm{b}}$ & 0.040 \\
Dressing $\%$ & $78.0^{\mathrm{b}}$ & $82.0^{\mathrm{a}}$ & 0.034 \\
\hline
\end{tabular}

Different letters in the same row indicate significant differences $(p<0.05)$.

\section{Dressing percentages}

The HE had significant $(p<0.05)$ effects on dressing proportions. The dressing percentages of $\mathrm{T} 1$ birds was higher compared to T2 and the control birds $(82$, vs. $77.5,78 \%, p<0.05)$, Table 3 .

\section{Carcass cuts}

Most of carcass cuts were not affected by the supplementation of the HE, however, the percentages of neck and wing significantly reduced in T1 compared to these in T2 and the control birds (Table 3).

\section{Lymphoid organs}

The effects of treatments on immune related tissues are shown in Table 4. Spleen and bursa percentages were affected $(p<0.05)$ by $\mathrm{HE}$ supplementation. The bursa of $\mathrm{T} 2$ birds had the highest percentages compared to $\mathrm{T} 1$ and the control birds (0.145 vs. 0.11 , $0.12 \%, p<0.05)$. A similar trend was observed for spleen percentage where $\mathrm{T} 2$ birds had more spleen weight compared to T1 and the control birds ( $0.20 \mathrm{vs}$. $0.17,0.19 \%, p<0.05)$, Table 3 .

\section{Muscle quality}

The incidence of muscle abnormalities (white striping or white striping combined with wooden) at different ages of slaughter (34, 41, and 48 d) was shown in Table 4. Our study revealed that the addition of herb mix had great $(p<0.05)$ impact on the incidence of muscle abnormalities, and this effect was very clear at 34 days of age. In this context, the incidence of white striping combined with wooden abnormalities in group T1 and T2 was 0\% while in control group (C) it was $35.2 \%$. At slaughter age, the incidence of white striping in group T1 and T2 was lower than in the control group (C) (28.1 and 29.8 vs. 38.5\%) respectively. At higher age of slaughtering (41 and $48 \mathrm{~d}$ ), the effect of herbs extract on the incidence of muscle abnormalities was less if compared to 34 days of age. Breast fillets at age 41 and 48 did not show any normal cases in all treatments. The incidence of white striping in group T1 and T2 at age 41 (32.8 and 19.5 vs. 39.2) and age 48 (23.5 and 25.5 vs. 33\%) was lower than the control group.

\section{DISCUSSION}

\section{Feed intake}

The HE had a significant effect on feed intake of treated chicks. The highest intake was in birds consuming the HE at the two levels compared to the control birds. Similar findings were observed in previous researches where feed intake was higher in broilers fed $0.2 \mathrm{ml} / \mathrm{L}$ of medicinal herb extract (Abo Omar et al., 
Table 4 - Percentages of normal, white striping (WS) and WS plus wooden meat abnormalities of broilers supplemented with herb extract (HE) at different ages. The basal diet (control, C) which is similar to regular broiler starter diets. While the experimental treatments T1 and T2 birds were fed the diets as in control but was supplemented with the herb extract at levels of 0.2 and $0.3 \mathrm{ml} / \mathrm{L}$ in drinking water.

\begin{tabular}{|c|c|c|c|}
\hline & C-d 34 & T1-d 34 & T2-d 34 \\
\hline Normal & $26.4^{b}$ & $71.9^{a}$ & $70.2^{a}$ \\
\hline white striping & $38.5^{\mathrm{a}}$ & $28.1^{\mathrm{b}}$ & $29.8^{\mathrm{b}}$ \\
\hline \multirow[t]{2}{*}{ white striping + wooden meat } & $35.2^{\mathrm{a}}$ & $0.0^{b}$ & $0.0^{\mathrm{b}}$ \\
\hline & C-d 41 & T1-d 41 & T2-d 41 \\
\hline Normal & 0 & 0 & 0 \\
\hline white striping & $39.2^{\mathrm{a}}$ & $32.8^{a}$ & $19.5^{b}$ \\
\hline \multirow[t]{2}{*}{ white striping + wooden meat } & 60.8 & 67.2 & 80.5 \\
\hline & C-d 48 & T1-d 48 & T2-d 48 \\
\hline Normal & 0 & 0 & 0 \\
\hline white striping & 33.0 & 23.5 & 25.5 \\
\hline white striping + wooden meat & 67.0 & 76.5 & 74.5 \\
\hline
\end{tabular}

Different letters in the same row indicate significant differences $(p<0.05)$.

2016). However, anise seeds had negative effects on feed intake when fed at levels from 1 to $10 \mathrm{~g} / \mathrm{kg}$ ration (Yazdy et al. (2014). The positive effects of HE on feed intake presented in this research could be related to improvement of appetite (Raju et al. 2004; Abo Omar et al., 2016).

\section{Body weight}

The two supplemental levels of the HE (0.2 and $0.3 \mathrm{ml} / \mathrm{L}$ ) improved broiler growth. The same effect of medicinal plant extract on broilers body weight were reported by Abo Omar et al. (2016). Our findings were in disagreement with previous research when anise seeds had no effect on broilers growth Yazdy et al. (2014). The essential fatty acids (linolenic and linoleic) in black seeds might explain our results regarding the improvement in broilers growth (Murray et al., 1991). A dose of $5 \mathrm{~g} / \mathrm{kg}$ of thyme had significant improvement on broilers weight and feed conversion ratio (Toghyani et al., 2010). Similar trend was reported by Najafi \& Turki (2010) where thyme-included diet had significantly increased broilers body weight and feed conversion ratio, however, negative effects of thyme were observed on broilers performance (Demir et al., 2008; Tekeli et al., 2006).

\section{Feed conversion ratio}

Best feed conversion ratio was observed in broilers fed high level of HE $(0.3 \mathrm{ml} / \mathrm{L})$ levels. This finding agrees with previous research where medicinal herb extract had significant improvement in feed efficiency, 8 to 11 (Abo Omar et al., 2016). Similar results were reported with anise seeds when fed to broilers (Yazdy et al., 2014). The suppression of gram-negative bacteria and clostridium with other growth depression agents along with the improvement of feed nutrient digestion and absorption can explain the better general performance and the feed conversion ratio (Abd El -Latif et al., 2004; El-Gendy et al., 1996; Ghazalah \& Ibrahim, 1996). The positive advantages HE on animals' performance could be achieved through the antioxidants, antibacterial, antifungal and antiprotozoal agents (Leung \& Foster, 1996). The alteration of some physiological and chemical functions of the digestive tract by some plant metabolites such as isoprene derivatives, flavonoids and glucosinolates might cause the observed effects (Baratta, et al. 1998; Horton et al., 1991; Jamroz et al., 2003). Body weight gain, feed conversion ratio and protein efficiency ratio significantly improved for chicks fed diets supplemented with fenugreek at rate of $0.5 \%$ or $1.5 \%$ as compared to the control diet (Elbushra, 2012).

Similarly, supplementation of chamomile flowers at level of $2.5 \mathrm{~kg} / \mathrm{ton}$ of broiler diet improved growth performance and feed conversion (Abaza et al., 2008). There is a debate on the real effects of nettle (a component of our plant extract) on broilers performance. The carvacrol in nettle has stimulatory effects on pancreatic secretions (Mansoub, 2011) by increasing the secretions of digestive enzymes more amounts of nutrients like amino acids can be digested and absorbed from the digestive tract and thereby improve carcass traits. Abedin etal. (2019) reported that the high amount of bioactive compounds in Chinese herbal medicine byproducts confer several nutritional and health benefits. Similarly, medicinal plant leaf meal improved broilers growth and feed conversion ratio through improvement of anti-oxidative capacity without negative effects on birds' health (Daramola, 2019). 


\section{Visceral tissues}

HE had no effects on abdomen fat, pancreas, and heart. Proportions of liver weights to live weight was lowest in birds fed $300 \mathrm{ml} / \mathrm{L}$ of the extract. However, the two levels of the extract reduced the percentages of gizzard, crop and intestine proportions. Abo Omar et al. (2016) reported similar results for broilers fed medicinal plant extract.

\section{Dressing percentages}

Feeds supplemented by the HE resulted in higher dressing proportions compared to the control birds. Similar trends were observed in previous research (Issa \& Abo Omar, 2013; Abo Omar et al., 2016), where medicinal plants improved dressing percentages. The dressing proportions in this research were relatively higher compared to what was reported as our feeding period was one week longer.

\section{Carcass cuts}

Most of the carcass cuts were not affected by the supplementation of the HE, however, percentages of neck and wing were significantly reduced. Similar results were reported previously (Abo Omar et al., 2016; Issa \& Abo Omar, 2013, Abo Omar et al., 2016).

\section{Lymphoid organs}

Both bursa and spleen relative weights increased in birds supplemented with HE. Yazdy et al. (2014) reported that anise seeds had no effect on spleen but caused significant increase in bursa weight. However, medicinal herb extracts reduced the weights of spleen and bursa of broilers (Abo Omar et al., 2016).

The low mortality and the good performance of broilers can be explained by the enhancement of the immune system as indicated by larger spleen and bursa weights.

\section{Muscle quality}

Inclusion of the herbs mix in the drinking water of chicks showed significant reduction in the incidence of muscle abnormalities (white striping and wooden) at 34 days of age, day of slaughter. Herbal mix that has been employed in this study contains several functional ingredients such as thymol, carvacrol, antioxidants, serotonin, etc as well as many of essential minerals (calcium, phosphorus, iron, zinc and magnesium). In general, the etiological origin of these muscle abnormalities is still unclear but there are several hypotheses that can explain the potential etiology. It was found that the incidence of muscle abnormalities was commonly in fast-growing and high-breast development in modern broiler hybrids. These broiler hybrids were characterized by hypoxia which was attributed to low density of blood capillaries and insufficient oxygen and nutrients supply (Sihvo et al. 2018; Boerboom et al., 2018). Another hypothesis, the tremendous growth in breast muscle may generate extra compression over the artery of pectoral muscle which contributes to more reduction in oxygen and nutrients supply to muscle. Several researchers found that the severity of histological lesions in white striped and wooden breast increases by moving from the inner core of pectoralis major muscle towards the surface of muscle which supports the previous hypothesis (Clark \& Velleman, 2016; Soglia et al., 2016; Baldi et al., 2018). At low age of slaughter (in our case 34 days), the impairment in the oxygen and nutrients supply due to growth may be very low which. Therefore, the birds may be able to supply of functional ingredients in the mix herbs to their muscle which contributed to reduce the incidence of white striping and wooden muscle abnormalities. On the hand, at high ages of slaughter (41 and 48 days), the muscles growth is usually very high and the impairment of oxygen and nutrients supply is sharply affected. Therefore, the functional nutrients in herb mix may not reach the affected muscles, this may explain why at high ages of slaughter, there was no effect of herbs mix on the incidence of white striping and wooden muscle abnormalities. In conclusion, the HE had several advantages when supplemented to broilers. Significant improvement in body weights, FCR and dressing percentages were achieved. Application of $\mathrm{HE}$ reduced the incidence of muscle abnormalities then broiler meat quality. Our results were comparable to Cobb 500 standards.

\section{CONFLICT OF INTERESTS}

The authors declare no potential conflict of interest.

\section{ACKNOWLEDGEMENT}

Authors of this article thank Bajoura Company (Tulkarm) for supplying the plant extract and Palestine Poultry Company (PPC) for funding the project

\section{REFERENCES}

Abaza IM, Shehata, MS, Shoieb MA, Hssan II. Evaluation of some natural feed additives in growing chicks' diets. International Journal of Poultry Science 2008;9;872-879.

Abd El -Latif SA, El -Yamany AT, Eman AF. Evaluation of using different levels and sources of medicinal herbs in growing Japanese quail diets. Egyptian Journal of Nutrition and Feeds 2004;7;69 -81. 
Abedin A, Pei Z, Qingzhen Z, Zewei S. Application of traditional Chinese herbal medicine byproducts as dietary feed supplement and antibiotic replacement in animal production. Current Drug Metabolism 2019;30(1):54-64.

Abo omar J, Hejazi A, Badran R. Performance of broilers supplemented with natural herb extract. Open Journal of Animal Sciences 2016;6(1):6874

Bakhiet AO, Adam SEl. Therapeutic utility, constituents and toxicity of some medicinal plants: a review. Veterinary Human Toxicology 1995;37:255258.

Baldi G, Soglia F, Mazzoni M, Sirri F, Canonico L, Babini E, et al. Implications of white striping and spaghetti meat abnormalities on meat quality and histological features in broilers. Animal 2018;12(1):164-173.

Baratta MT, Dorman HJD, Deans SG, Biondi DM, Ruberto G. Chemical composition, antimicrobial and anti oxidative activity of laurel, sage, rosemary, oregano and coriander essentials oils. Journal of Essential Oil Research 1998;10(6):618-627.

Boerboom G, van Kempen T, Navarro-Villa A, Pérez-Bonilla A. Unraveling the cause of white striping in broilers using metabolomics. Poultry Science 2018;97(11):3977-3986.

Clark, DL, Velleman, SG. Spatial influence on breast muscle morphological structure, myofiber size, and gene expression associated with the wooden breast myopathy in broilers. Poultry Science 2016:95(12):29302945.

Daramola OT. Medicinal plant leaf meal supplementation in broiler chickens diets: effect on performance characteristics, serum metabolite and antioxidant status. Animal Research International 2019;16(2):33343342

Demir E, Kilinc K, Yildirim Y, Dincer F, Eseceli H. Comparative effects of mint, sage, thyme and flavomycin in wheat -based broiler diets. Archiva Zootechnica 2008;11:54-63.

Elbushra M. Effect of dietary fenugreek seeds (trigonella foenum) as natural feed addition on broiler chicks' performance. Journal of Science and Technology 2012;13:27-33.

EL-Gendi GM. Effect of Feeding Dietary Herbal Feed Additives on Productive and Metabolic Responses of Broiler Chicks. Egyptian Poultry Science 1996;16:395-412.

Foster S, Duke J. A field guide to medicinal plants and herbs: of Eastern and Central North America. Boston: Houghton Mifflin; 1999.

Ghazalah AA, Ibrahim AA. The possibility of using some edible and aromatic oils in the nutrition of Muscovi ducks. Egypt Poultry Science $1996 ; 11: 305-328$.

Gill A, Delaquis P, Russo P, Holley R. Evaluation of antilistreial action of cilantro oil on vacuum packed ham. Intertional Journal of Food Microbiology 2002;73:83-92.

Gupta K, Thakral S, Arora K, Chowdhary M. Structural carbohydrate and mineral seeds. Indian Coca Arecenut and Species Journal 1996;20:120.

Horton GMJ, Fennell M, Prasad BM. Effect of dietary garlic (allium sativum) on performance, carcass composition and blood chemistry changes in broiler chickens. Canadian Journal of Animal Science 1991:71:939942.

Issa K, Abo Omar J. Effect of garlic powder on performance and lipid profile of broilers. Open Journal of Animal Science 2012;2:62-68.

Jamroz D, Orda J, Kamel C, Williczkiewicz A, Wertelecki T, Skorupin'Ska J. The influence of phytogenic extract on performance, nutrients digestibility, carcass characteristic and gut microbial status in broiler chickens. Journal of Animal Feed Science and Technology 2003;12:583596

Janssen AM. Antimicrobial activities of essential oils: a pharmacognostical study. Journal of Essential Oil Research 1989;10:618-627.

Kolacz R, Switala M, Gajewczyk P. Herbs as agents affecting the immunological status and growth of piglets weaned with body weight deficiency. Journal of Animal Feed Science 1997;6:269-279.

Kuttappan VA, Brewer V, Jason K. Apple JK, Owens CM. Influence of growth rate on the occurrence of white striping in broiler breast fillets. Poultry Science 2012;91(10):2677-2685

Lee MH, Lee HJ, Ryu PD. Public health risks: chemical and antibiotic residues review. Asian- Australasian Journal of Animal Science 2001;14:402413.

Leung AY, Foster S. Encyclopedia of common natural ingredients used in food, drugs and cosmetics. $2^{\text {nd }}$ ed. New York: John Wiley and Sons; 1996.

Mansoub NH. Comparison of effects of using nettle (urtica dioica) and probiotic on performance and serum composition of broiler chickens. Global Veterinaria 2011:6:247-250.

Mikaili P, Mohammad Nezhady MA, Shayegh J. Asghari MH. Study of antinociceptive effect of thymus vulgaris and foeniculum vulgare essential oil in mouse. International Journal for Academic Research $2010 \cdot 2 \cdot 374-376$

Mudalal S. Incidence of white striping and its effect on the quality traits of raw and processed turkey breast meat. Food Sciences of Animal Resources 2019;39(3):410-417.

Murray RK, Granner DK, Mayes P, Rodwell, VW. The text book of harpers biochemistry. 22 ${ }^{\text {nd }}$ ed. Los Altos: Appleton and Large; 1991.

Najafi P, Torki M. Performance, blood metabolites and immuno competence of broiler chicks fed diets included essential oils of medicinal herbs. Journal of Animal and Veterinary Advances 2010;9:1164-1172.

NRC - National Research Council. Nutrient requirements of poultry. $9^{\text {th }}$ ed. Washington: Academic Press; 1990.

Petracci M, Soglia F, Madruga M, Carvalho L, Ida E, Estévez M. Woodenbreast, white striping, and spaghetti meat: causes, consequences and consumer perception of emerging broiler meat abnormalities. Comprehensive Review in Food Science and Food Safety 2019;18(4):565-583.

Raju J, Patlolla JMR, Swamy MV, Rao CV. Diosgenin, a steroid saponins of trigonella foenum graecum (feungreek), Inhibitsazoxymethane -induced aberrant crypt foci formation in F344 Rats and induces apoptosis in HT-29 human colon cancer cells. Cancer Epidemiology, Biomarkers \& Prevention 2004;13:1392-1398.

SAS Institute. SAS user's guide: statistics. Version 8.0 .Cary; 2002.

Sihvo HK, Airas N, Lindén J, Puolanne, E. Pectoral vessel density and early ultrastructural changes in broiler chicken wooden breast myopathy. Journal of Comparative Pathology 2018;161(5):1-10.

Skrabka -Blotnicka T, Rosin'ski A, Przysie -Zzna,Woloszyn J. Elminowska -Wenda, G. Effect of dietary formulation supplemented with herbal mixture on goose breast muscle quality. Report I. The Effect on the chemical composition. Archives für Geflügelkunde 1997;61:135-138.

Soglia F, Mudalal S, Babini E, Di Nunzio M, Mazzoni M, Sirri F, et al. Histology, composition, and quality traits of chicken Pectoralis major muscle affected by wooden breast abnormality. Poultry Science 2016:95(3):651-659 
Tekeli A, Çelik L, Kutlu HR, Gorgulu M. Effect of dietary supplemental plant extracts on performance, carcass characteristics, digestive system development, intestinal microflora and some blood parameters of broiler chicks. Proceedings of the 12th European Poultry Conference; 2006; Verona. p.10-14

Toghyani M, Tohidi M, Gheisari AA Tabeidian SA. Performance, immunity, serum biochemical and hematological parameters in broiler chicks fed dietary thyme as alternative for an antibiotic growth promoter. African Journal of Biotechnology 2010;9:6819-6825.

William P, Losa R. The use of essential oils and their compounds in poultry nutrition. World Poultry 2001;17:14-15.
Yazdy FF, Toghiani M, Ghalamkari GLandi N. Anise seed (Pimpinella anisum L.) as an alternative to antibiotic growth promoters on performance, carcass traits and immune responses in broiler chicks. Asian Pacific Journal of Tropical Disease 2014;4(6):447-451.

Zaid A, Abu-Khalaf N, Mudalal S, Petracci M. Differentiation between normal and whitestriped turkey breasts by visible/near infrared spectroscopy and multivariate data. Food Science of Animal Resources 2020;40(1):96-105. 